\title{
RELAÇÕES ENTRE PEDAGOGIA HISTÓRICO-CRÍTICA, PSICOLOGIA HISTÓRICO-CULTURAL E O CONCEITO DE ATIVIDADE DE LEONTIEV
}

\author{
RELATIONS BETWEEN HISTORICAL CRITICAL PEDAGOGY, HISTORICAL \\ CULTURAL PSYCHOLOGY AND LEONTIEV ACTIVITY CONCEPT \\ Clarice Gonçalves Rodrigues Alves ${ }^{1}$ \\ Lana Cristina Barbosa de Melo ${ }^{2}$ \\ Virgínia Marne da Silva Araújo dos Santos ${ }^{3}$
}

\section{RESUMO}

O objetivo deste artigo é apresentar a Teoria da Atividade desenvolvida pelo psicólogo russo Leontiev e suas contribuições para o processo de aprendizagem. Valendo-se de reflexões de autores da Pedagogia Histórico-crítica e da Psicologia Histórico-cultural, pretende-se relacionar política, didática e aprendizagem, uma vez que estes elementos são indissociáveis para compreender o panorama educacional contemporâneo. Buscou-se compreender o significado de educação, prática social, atividade, atividade pedagógica para, posteriormente, associá-las com práticas educativas que promovam mudanças significativas nos sujeitos.

\section{Palavras-chave: Pedagogia Histórico-crítica - Psicologia Histórico-cultural - Atividade - Leontiev.}

\begin{abstract}
The purpose of this article is to present the Theory of Activity from the Russian psychologist Leontiev and its contributions to the learning process. Taking advantage of various author reflections on the Historical Critical Pedagogy and Historical Cultural Psychology, in order to link policy, teaching and learning, as these elements areinextricably linked to understanding the contemporary educational scene. We sought to understand the meaning of education, social practice, activity and pedagogical activity to, later associate them with educational practices that promote significant changes in the subjects.
\end{abstract}

Key-words: Historical Critical Pedagogy -Historical Cultural Psychology -Activity Leontiev

\section{INTRODUÇÃO}

A educação é um fenômeno complexo e dinâmico, requer diálogo, trocas e estudos sobre seus fins e objetivos. A abordagem dos conteúdos e a metodologia aplicada no processo educativo são fundamentais para desenvolver as capacidades intelectuais dos estudantes e promover tanto a ampliação dos sentidos quanto práticas sociais que desenvolvam os sujeitos cognitivamente e socialmente.

\footnotetext{
1 Mestranda em Educação (UERR/IFRR). Professora de História do IFRR-CNP. Email: clarice.duarte@ifrr.edu.br

${ }_{2}^{2}$ Mestranda em Educação (UERR/IFRR). Professora de Estrutura e Funcionamento da Educação Especial. Email: lana.melo@ifrr.edu.br

${ }^{3}$ Professora de Psicologia Geral do IFRR-CBV.E-mail: virginia.santos@ifrr.edu.br

Revista Labor Fortaleza/CE, jan/jul 2017 Vol. 01, nº 17, p. 27-41

ISSN 1983-5000
} 
A falta de conexão entre a teoria acadêmica e a prática social dos alunos é refletida na dificuldade que alguns estudantes têm de aplicar os conhecimentos em situações cotidianas, fato que merece ser analisado, uma vez que a educação deve primar pelo desenvolvimento pessoal e coletivo. Este estudo contrapõe-se às concepções de escola que desconsideram os conteúdos e buscam a mera sociabilização, pois entende que a compreensão humana é oriunda da reflexão e análise de conhecimentos historicamente construídos, e a escola tem o papel de transmití-los e promover sua assimilação.

O artigo buscou compreender como o ensino crítico e focado nos conteúdos pode contribuir qualitativamente para a educação e contou com contribuições de autores da Pedagogia Histórico-Crítica, como: Demerval Saviani, Newton Duarte, Terezinha Rios, Gaudêncio Frigotto. Da mesma forma, valeu-se de autores da Psicologia Histórico-Cultural, com destaque para Leontiev e a Teoria da Atividade, que, nesta proposta é basilar para ampliar a discussão sobre a relação entre política, aprendizagem e educação.

\section{EDUCAÇÃO E SOCIEDADE}

A educação vincula-se à ética, à cultura, às leis e aos valores sociais e tem importância econômica e política. Do ponto de vista mercadológico, há uma série de bens e serviços relacionados à educação; também há uma relação direta com a preparação dos sujeitos para o trabalho e para a transformação de si e do meio. A educação também é fruto da ação humana, quando os homens, imbuídos de escolhas políticas elegem saberes que devem ou não ser assimilados por gerações futuras. De acordo com Saviani (2012, p.13), "o trabalho educativo é o ato de produzir, direta e intencionalmente, em cada indivíduo singular, a humanidade que é produzida histórica e coletivamente pelo conjunto dos homens".

Cada sociedade atribuiu ao longo do tempo um significado para a educação. $\mathrm{O}$ homem primitivo, por exemplo, aprendia na ação cotidiana, de forma coletiva, sem instituição, pois a natureza era sua escola e a partir das necessidades materiais exigidas por ela, transformava-a, aprendia e ensinava. Na Antiguidade, o saber era obtido no seio familiar, nos clãs, genos, tribos, na ágora, no treinamento para as guerras e, geralmente, era restrito, ou seja, somente determinados grupos ou indivíduos no contato com seus pretores e mestres podiam acessar o saber historicamente construído. Na Idade Média, as corporações de ofício e as instituições religiosas educavam à sua maneira, tendo o trabalho como premissa. $\mathrm{O}$ distanciamento na natureza e o aumento das técnicas produtivas passam a exigir que a 
aprendizagem tenha seu espaço reservado e garantido até chegarmos à institucionalização escolar contemporânea, marcada fortemente por elementos comuns à lógica capitalista: produtividade, competividade, controle de tempo, espaço e recursos.

A sociedade atual cultua a educação e a instituição escolar e, contraditoriamente, retira dela o essencial, atribui significados e tarefas que não lhe cabem e a esvaziam de sentido. Assim, faz-se necessário voltar ao ponto de partida, questionar seus objetivos e, sobretudo, o modelo educativo que temos para, por fim, termos clareza da educação que almejamos. Ao fazer uma crítica sobre as inversões e confusões que descaracterizam o trabalho escolar Saviani (2012, p.15) aponta que, ao final do ano letivo pode-se constatar que:

[...] fez-se de tudo na escola; encontrou-se tempo para toda espécie de comemoração, mas muito pouco tempo foi destinado ao processo de transmissãoassimilação de conhecimentos sistematizados. Isto quer dizer que se perdeu de vista a atividade nuclear da escola, isto é, a transmissão de instrumentos de acesso ao saber elaborado.

Nossa sociedade relegou à educação um papel fundamental. Percebe-se a existência de diferentes tipos de escolas adequadas para satisfazer ou atender interesses de grupos cada vez mais diversos. O número de instituições de ensino cresceu, o acesso foi facilitado, o tempo do estudante na escola aumentou, porém, a realidade escolar não revela um aprimoramento do humano, de suas práticas sociais e de suas instituições. Falta um entendimento maior dos fins da própria educação e de seus meios. A educação é uma prática social que deveria transformar integralmente e qualitativamente os seres humanos por meio da apreensão do saber acumulado ao longo de sua História.

Enquanto prática social, é ação e conceito; teoria e prática; é um fenômeno realizado pelos seres humanos e está em constante movimento. O ser humano, diferentemente das demais espécies, objetiva-se e apropria-se da cultura material e imaterial de outros homens e tanto cria novas necessidades quanto recria a si próprio. Então, se a educação é fundamental para humanização dos sujeitos, por que não nos tornamos mais humanos nos bancos escolares? Na obra 'O desenvolvimento do Psiquismo', Leontiev (1978, p.272) pontua:

As aquisições do desenvolvimento histórico das aptidões humanas não são simplesmente dadas aos homens nos fenômenos objetivos da cultura material e espiritual que as encarnam, mas são aí apenas postas. Para se apropriar destes resultados, para fazer deles as suas aptidões, "os órgãos de sua individualidade", a criança, o ser humano, deve entrar em relação com os fenômenos do mundo circundante através doutros homens, isto é, num processo de comunicação com eles. 
Assim, a criança aprende a atividade adequada. Para sua função, este processo é, portanto, um processo de educação.

Esta compreensão de educação e da ação humana no mundo que considera elementos como política, prática social e atividade é inerente também aos pressupostoas da Pedagogia Histórico-Crítica. A educação é percebida como uma construção coletiva que prima pela educação integral do homem, permitindo a compreensão de suas contradições e as dinâmicas sociais realizadas no mundo dos fenômenos materiais. Trivinos (2006, p. 122) corrobora neste sentido ao afirmar que:

[...] trazendo uma visão de mundo antagônica, a Teoria Crítica, com a sociologia do conflito, afirma que a sociedade não é uma entidade orgânica, ao contrário, é informada por múltiplos interesses conflituosos, contraditórios que estão permanentemente em disputa, demarcando embates de toda natureza. O conflito aqui é entendido como uma das características constituintes da sociedade, e não um "defeito" que foge ao padrão da harmonia social idealizada no funcionalismo.

\section{PEDAGOGIA HISTÓRICO-CRÍTICA E EDUCAÇÃo}

A Pedagogia Histórico-Crítica esclarece que a educação é influenciada por elementos sócio-políticos; que há uma relação dialética no processo educativo; e que há critérios de desenvolvimento a serem observados. A economia, o contexto social, as leis que a orientam, têm um objetivo e são permeadas de valores que contribuem para que a educação seja um processo conflitivo, dinâmico e transformador. Também questiona modismos e tendências que minimizam o papel do educador, dos conteúdos e das práticas sociais do processo educativo. "A educação não é apenas um processo institucional e instrucional, seu lado visível, mas fundamentalmente um investimento formativo do humano, seja na particularidade da relação pedagógica formal, seja no âmbito da relação social coletiva" (SEVERINO, 2006, p.621). Demerval Saviani nos esclarece como se deu este processo e porque optou por denominá-la "Pedagogia Histórico-crítica":

[...] a expressão histórico-crítica traduzia de modo pertinente o que estava sendo pensado. Porque exatamente o problema das teorias crítico reprodutivistas era a falta de enraizamento histórico, isto é, a apreensão do movimento histórico que se desenvolve dialeticamente em suas contradições. A questão em causa era exatamente dar conta desse movimento e ver como a pedagogia se inseria no processo da sociedade e de suas transformações. Então, a expressão histórico-crítica, de certa forma, contrapunha-se a crítico reprodutivista. É crítica, como esta, mas diferentemente dela, não é reprodutivista, mas enraizada na história (SAVIANI, 2012, p.140-141) 
Esta concepção de educação acredita que o pleno desenvolvimento dos sujeitos é incompatível à adaptação aos modelos da sociedade capitalista vigente. Portanto, deve haver um direcionamento pedagógico que atrele processos psíquicos e relações sociais e que perceba a transformação dos objetos e dos seres humanos como processos indissociáveis. Para Newton Duarte (2013, p.46):

\begin{abstract}
O indivíduo forma-se apropriando-se dos resultados da história social e objetivandose no interior dessa história, ou seja, sua formação realiza-se por meio da relação entre objetivação e apropriação. Essa relação efetiva-se sempre no interior de relações concretas com outros indivíduos, que atuam como mediadores entre ele e o mundo humano, o mundo da atividade humana objetivada. A formação do indivíduo é, portanto, sempre um processo educativo, mesmo quando esta educação, na vida cotidiana, se realiza de forma espontânea, isto é, quando não há uma relação consciente para com o processo educativo, tanto da parte de quem está sendo educado quanto de quem está educando.
\end{abstract}

Cabe aqui apontarmos os seguintes questionamentos: será que a classe dominante está interessada no desenvolvimento da escola e dos estudantes? Será que está empenhada numa mudança real ou na preservação de seus interesses? Será que é possível aplicar uma pedagogia que contraponha interesses e valores hegemônicos? $\mathrm{E}$ ainda: será que o construtivismo e o lema "aprender a aprender" vai ao encontro dos educandos, objetivando seu desenvolvimento psíquico, social e econômico? Embora Marx não tenha escrito tratados específicos para a educação, o texto a seguir, extraído do manuscrito anexo a 'Trabalho assalariado e capital' faz uma crítica à classe burguesa que bem caberia ao contexto atual:

\begin{abstract}
Uma outra reforma muito apreciada pelos burgueses é a educação e, particularmente, a educação profissional. Não pretendemos realçar a absurda contradição segundo a qual a indústria moderna substitui cada vez mais o trabalho complexo pelo trabalho simples para o qual não há necessidade de formação (...) Não queremos, finalmente, realçar que a formação intelectual, se o operário a tivesse, não exerceria influência direta sobre o seu salário, que a instrução geral depende do nível das condições de vida e que o burguês entende por educação moral é farto de princípios burgueses em que afinal de contas a classe burguesa não possui os meios nem o desejo de oferecer ao povo uma educação verdadeira (MARXS \& ENGELS, 1849 apud LOMBARDI \& SAVIANI, 2005, p.58).
\end{abstract}

A Pedagogia Histórico-crítica reitera a importância dos conteúdos, do conhecimento historicamente construído, da formação profissional de professores e alunos (agentes da mudança) e da escola enquanto espaço - não de mera socialização, mas de trocas sociais e culturais necessárias ao desenvolvimento das capacidades cognitivas humanas. Critica o ensino tradicional reprodutivista assim como os modelos construtivistas. Saviani 
(2012, p.16-17) nos incita à voltarmos ao clássico, entendido como aquele elemento que resistiu ao tempo, que é duradouro, permanente:

\footnotetext{
Ora, clássico na escola é a transmissão- assimilação do saber sistematizado. Este é o fim a atingir. É aí que cabe encontrar a fonte natural para elaborar os métodos e as formas de organização do conjunto das atividades da escola, isto é, do currículo. E aqui nós podemos recuperar o conceito abrangente de currículo: organização do conjunto de atividades nucleares distribuídas no espaço e tempo escolares. Um currículo é, pois, uma escola funcionando, quer dizer, uma escola desempenhando a função que lhe é própria.
}

A observação de que a escola deve desempenhar a função que lhe corresponde é necessária no contexto atual. O saber historicamente construído precisa ser transmitido e assimilado, ou seja, deve ser socializado para que, a partir dele, ocorram mudanças e superações em nível individual e coletivo. "O tipo de educação escolar defendido pelas teorias pedagógicas hegemônicas nas últimas décadas tem limitado o trabalho educativo à satisfação das necessidades cotidianas imediatas e puramente adaptativas" (SAVIANI, 2012, p. 215). A Pedagogia Histórico-crítica propõe a transformação dos indivíduos e a socialização dos conhecimentos científicos, artísticos e filosóficos e, portanto, reitera a importância dos conteúdos e dos conceitos, negando tanto à transmissão de conteúdos vazios e insipientes na escola tradicional quanto às tendências construtivistas que não têm melhorado o contexto educacional.

Newton Duarte (2001) afirma que a Pedagogia Construtivista em seus quatro principais lemas valorativos vai contra a educação crítica e transformadora. Primeiramente, por valorizar a aprendizagem individual em detrimento da coletiva, ou seja, minimiza ou elimina a necessidade do coletivo, do professor, de alguém que conduza o processo, desvalorizando o ato de ensinar. Como segundo ponto, confere demasiada importância ao método científico e ao processo mais que o produto, fato que desmerece o conhecimento construído historicamente. Revela que a atividade deve ser direcionada e dirigida pela prática cotidiana nos alunos. Certamente, este fator é importante, desenvolver atividades a partir dos contextos, no entanto, percebe-se o extremismo e a aclamada espontaneidade convertendo-se em a falta de direcionamento de educadores e das instituições. O quarto elemento citado é formação de indivíduos com grande capacidade adaptativa. Com este ponto, o autor finaliza que uma pedagogia crítica que pretenda defender a classe trabalhadora não pode defender este lema, uma vez que impossibilita a formação de um projeto coletivo e a superação da sociedade capitalista. 
É evidente que a visão marxista sobre educação tem um potencial apontado a uma profunda transformação da sociedade capitalista e de sua superação, em relação a outras concepções educacionais. E isso advém primeiramente de sua própria natureza epistemológica e metodológica: situando a educação como prática social, trata de encaminhar as reflexões tendo em vista a prática. Nesse sentido, o exercício teorizante só pode ser verdadeiro se se tornar ação. A atividade intelectual tem seu momento, porém nunca desligada de proposições concretas que devem apontar para a transformação (LOMBARDI \& SAVIANI, 2005, p.44).

Ao aplicar-se uma pedagogia centrada somente na teoria ou no método, corre-se o risco de desqualificar o ato de ensinar. "Convém às classes dominantes que o professor interiorize que ninguém ensina nada a ninguém. Assim, a própria (escola) se desobriga do ensino, do preparo do cidadão. Todos os fracassos passam a ser creditados a pessoas, individualmente" (ALMEIDA, 1986, p.148). Ao aplicar-se uma pedagogia que ressalta a importância das relações sociais, a educação volta a adquirir dois significados importantes: o de colaboradora para o processo de hominização e de humanização dos sujeitos.

Bernard Charlot (2005) ressalta que a escola não tem cumprido uma função social importante: a distribuição das posições sociais, pois, apesar dos discursos proferidos por educadores e pela sociedade apontarem a escola como possível alavanca para o "sucesso" pessoal e profissional, percebe-se na prática a manutenção das posições socioeconômicas já orientadas para tais ou quais sujeitos. A escola não está abrindo novas perspectivas e a ascensão social através da educação e do processo formativo é vivenciada por uma minoria. Reitera, inclusive, que muitos educadores rotulam o valor humano por um grau escolar e percebem os títulos como referência social ou aquisição de status. Estes discursos podem/devem ser superados, posto que, colaboram para a manutenção e reprodução do sistema capitalista com suas regras, adaptações, disciplinamento e tensões que não mudam a realidade escolar.

O saber socialmente construído pela humanidade deve ser apropriado por todos os membros da sociedade, cabendo à escola sistematizá-lo. Para Terezinha Rios (2008), a escola é caracterizada como um espaço para transmissão sistemática do saber acumulado pela sociedade para que os indivíduos se capacitem e colaborem para a construção desta própria sociedade. Portanto, os estudantes devem ser agentes, devem ser críticos e devem inquerir e questionar valores, sistemas, modos de ser e agir de seu contexto social. Neste sentido, é preciso analisar com profundidade as tendências pedagógicas e os valores e visões de mundo que estão presentes no dia a dia da sala de aula. 


\begin{abstract}
A concepção pedagógica burguesa tem sido sistematicamente tratada e defendida pela intelectualidade orgânica dessa classe. De modo geral, a exposição do conteúdo da concepção pedagógica burguesa, entre nós, tem sido analisada por Newton Duarte em uma aguda crítica ao que ele tem denominado "pedagogias do aprender a aprender" e que expressam o amplo leque de perspectivas ideologicamente ligadas ao liberalismo e sua versão novidadeira - o neoliberalismo.... Duarte inclui neste leque o escolanovismo, o construtivismo, a pedagogia das competências, a pedagogia dos projetos, a pedagogia do professor reflexivo etc. (LOMBARDI \& SAVIANI, 2005, p. 44).
\end{abstract}

$\mathrm{Na}$ área de educação, presenciamos discursos que abordam metodologias aparentemente inovadoras, mas que acabam sendo conteudistas e insubstanciais, pois estão dissociadas da totalidade da situação de vida do estudante, porém, percebe-se também um extremismo no ambiente escolar e a falta de conteúdos: "clássico na escola é a transmissãoassimilação do saber sistematizado. Este é o fim a atingir..." (SAVIANI, 2012, p.18). A falta de conteúdos, de dados, de debates, pesquisa, entre outros, impedem que o aluno e reflita criticamente sobre sua temporalidade, resultando em comodismo e indiferença com sua realidade pessoal, profissional e social. "Os conteúdos são fundamentais para que o aluno aprenda e sem conteúdos relevantes, conteúdos significativos, a aprendizagem deixa de existir, ela se transforma em um arremedo, ela transforma-se numa farsa". (SAVIANI, 2009, p.50). No extremo oposto, existe a escola reprodutivista, tecnicista, tradicional que utiliza a memorização, o método explicativo-ilustrativo sem ou com pouco diálogo e que não incita a criatividade tampouco a criticidade dos estudantes.

\title{
RELAÇÕES ENTRE PEDAgogia HISTÓRICO-CRÍTICA E PSICOLOGIA HISTÓRICO-CULTURAL
}

A Pedagogia Histórico-crítica e a Psicologia Histórico-cultural, por empregarem tanto conceitos teóricos quanto didáticas que favorecem o processo de assimilação dos conteúdos podem contribuir significativamente para o processo educativo, assinalando um caminho de mudança e que converge à importância tanto para o método de ensino quanto a aprendizagem. Ambas se opõem ao modelo de ensino tradicional e reprodutivista e à escola da sociabilidade que não ensina o aluno a pensar e transformar sua realidade.

O uso destas teorias possibilita que os educadores tenham uma visão crítica sobre a educação e percebam tendências pedagógicas que promovem a desvalorização e a falta de socialização dos saberes sistematizados pela humanidade. Neste sentido, poderiam colaborar para a construção de escolas que promovessem a passagem do saber espontâneo para o sistematizado através de conteúdos e não de técnicas de ensino. A atividade, cujo conceito Revista Labor Fortaleza/CE, jan/jul 2017 Vol. 01, nº 17, p. 27-41 ISSN 1983-5000 
abordaremos abaixo e a atividade pedagógica permitiriam que os sujeitos estabelecessem contatos com o mundo circundante por meio do desenvolvimento de seu psiquismo, pois: "a atividade essencial de uma escola é assegurar a relação cognitiva do aluno com a matéria, ou seja, a aprendizagem dos alunos, com a ajuda pedagógica do professor" (LIBÂNEO, 2001, p.22).

Lev Semenovitch Vigotski (1896-1934) foi o precursor da Psicologia Históricocultural. Ao perceber o homem enquanto ser histórico reitera que no processo de ensinoaprendizagem, o ambiente social e o biológico devem ser analisados. Propõe a construção social do conhecimento - o socioconstrutivismo - onde a relação do educador com o educando e entre os próprios educandos passam a compor a formação deste conhecimento, bem como a interação com a cultura.

$\mathrm{O}$ autor estabelece relações entre pensamento e linguagem e ressalta a necessidade de avaliar a criança pelo que está aprendendo em não pelo que já aprendeu, assim, busca entender os processos mentais envolvidos na compreensão do mundo. Percebe que é na interação com o outro, realizada através da linguagem, que ocorre a individualização, a construção e a internalização do conhecimento, ou seja, quando ocorre a internalização, a aprendizagem se completa. Sua teoria possui um critério de análise desenvolvimental e entende que o psiquismo humano é histórico e social. Através de suas pesquisas, pode-se questionar se a educação está, efetivamente, voltada para o pleno desenvolvimento dos indivíduos. Segundo suas concepções, o desenvolvimento cognitivo humano ocorre no ambiente social por meio da atividade. A atividade externa é a base para a constituição da atividade interna; e esta pode - e deve - ser potencializada no desenvolvimento das capacidades humanas.

Existem quatro conceitos fundantes em sua obra: Interação; Mediação, Internalização e Zona de Desenvolvimento Proximal (ZDP). Também ressalta a necessidade de orientar o desenvolvimento do ser humano através da interação social, da experimentação e uso das ferramentas para que os processos interpessoais se tornem intrapessoais. Revela que a atividade humana é mediada pelo uso de ferramentas que estabelecem, regulam, permeiam seu comportamento e sua ação no mundo. Fato que nos leva a reflexão acerca da atividade educativa e de como podemos contribuir para que conhecimentos elementares se transformem em superiores. Adentrando no conceito de Zona de Desenvolvimento Proximal (ZDP), podemos dizer que é distância entre o nível de desenvolvimento atual e o nível de 
desenvolvimento potencial. Neste ínterim, o estudante deve ser estimulado e o educador deve compreender como elevar este nível para que a internalização do saber se objetive.

Aleksei Nikolaevitch Leontiev (1903- 1979) também desenvolve seus estudos tendo como premissa que o desenvolvimento humano e sua relação com o mundo se dá pela atividade que este exerce. Suas pesquisas contribuem para o campo da Pedagogia, sobretudo, por questionar se a educação está, efetivamente, voltada para o pleno desenvolvimento dos indivíduos. Segundo Leontiev, o homem, enquanto ser social desenvolve-se de acordo com processos de apropriação e aquisição de conhecimentos, quando as atividades externas são interiorizadas e transformadas em atividades internas, mediante as relações estabelecidas com outros homens e com a natureza. Ele pontua também a necessidade de realizar a atividade como uma condição para sua realização. Também diferencia o homem enquanto espécie e o processo de humanização que, efetivamente, faz do homem, "homem humano".

\footnotetext{
[...] o homem não nasce dotado de aquisições históricas da humanidade. Resultando estas do desenvolvimento das ações humanas, não são incorporadas nem nele, nem nas suas disposições naturais, mas no mundo que o rodeia, nas grandes obras da cultura humana. Só apropriando-se delas, no decurso de sua vida, ele adquire propriedades e faculdades verdadeiramente humanas. Este processo coloca-o, por assim dizer, aos ombros das gerações anteriores e eleva-o muito acima do mundo animal. (LEONTIEV, 1978, p.282-283).
}

A Teoria da Atividade tem sua origem na teoria sócio-cultural de Vigotski. A atividade, portanto, é um sistema de ações com operações para alcançar um objetivo e este último deve coincidir com a motivação do sujeito. Sua teoria explica que, se o significado social da atividade não corresponde a um sentido pessoal do sujeito, cria-se a uma situação favorável à perda de sentido pessoal e coletivo.

El análisis de la actividad constituye el punto decisivo y el método principal del
conocimiento científico del reflejo psíquico, de la conciencia. En el estudio de las
formas de la conciencia social está el análisis de la vida cotidiana de la sociedad, de
las formas de producción propias de esta y del sistema de relaciones sociales; en el
estudio de la psiquis individual está el análisis de la actividad de los individuos en
las condiciones sociales dadas y en las circunstancias concretas que les ha tocado en
suerte a cada uno de ellos. (Leontiev, 1978, p. 17)

De acordo com Leontiév, através da atividade, ocorre um processo de internalização da atividade externa que resulta num reflexo psíquico da realidade: a consciência. Para o autor, a atividade não é uma reação, mas um sistema que tem estrutura, transições, desenvolvimento e transformações próprios. Para que haja atividade, três Revista Labor Fortaleza/CE, jan/jul 2017 Vol. 01, nº 17, p. 27-41 ISSN 1983-5000 
elementos devem existir: objeto, necessidade e motivo. O primeiro dá clareza do ponto a se percorrer, ele pode ser independente ou pode ser o resultado da atividade. A atividade requer uma necessidade, ou seja, este é o fator que a orienta e leva os indivíduos a agir e, por fim, temos o motivo.

Por atividade, designamos os processos psicologicamente caracterizados por aquilo a que o processo, como um todo, se dirige (seu objeto), coincidindo sempre com o objetivo que estimula o sujeito a executar esta atividade, isto é, o motivo. (LEONTIEV, 2014, p.68).

A necessidade constitui sua força interna; o motivo é o que a impulsiona e o move; já o objeto é o que a determina. Ela é a primeira condição para haver atividade, porém, somente no objeto que encontra sua determinação. Conforme Leontiev, uma vez que a necessidade encontra a sua determinação no objeto (se "objetiva" nele), o dito objeto torna-se motivo da atividade, aquilo que o estimula. O motivo é extremamente necessário e sem ele, a atividade perde sua razão de ser, o que levaria à alienação. Além de necessidade, motivo e objeto, a atividade é constituída por outros elementos: sujeito, operações, meios e produto.

Durante o processo de internalização, o conhecimento vai processando-se e atos mentais como pensamento e linguagem vão cristalizando-se em distintas ações e operações, simples ou complexas. As ações estão ligadas a um fim; já as operações são condições para a existência da atividade. As condições das atividades são variáveis, mesmo que os fins sejam os mesmos. A atividade se enriquece e é transformada de acordo com o contato com a realidade objetiva dos sujeitos.

[...] estudar como se formam as relações vitais do homem tais ou tais condições sociais históricas e que estrutura particular engendra dadas relações. Devemos em seguida estudar como a estrutura da consciência do homem se transforma com a estrutura da sua atividade. Determinar os caracteres da estrutura interna da consciência é caracterizá-la historicamente (LEONTIEV, 1978 p.92).

Deve-se ter em conta que a linguagem, enquanto construção humana e portadora de significados atribuídos pelos homens no tempo, isso é um fator indispensável para a atividade e para a compreensão da realidade social. A personalidade é entendida por ele como um momento interno da atividade e que se desenvolve a partir das relações estabelecidas pelos indivíduos. A Teoria da Atividade assim como a perspectiva histórico-cultural ressaltam que a educação não é a mera transmissão do patrimônio cultural, pois a apropriação da cultura pelo homem o objetiva e o transforma. 
De acordo com a Teoria da Atividade, consciência e atividade formam uma unidade dialética e estudar a consciência humana requer uma análise sobre como os homens em diferentes momentos realizam suas atividades. A realidade social determina a consciência humana. O homem é considerado um ente-espécie, um ser coletivo, um ser consciente, um ser que trabalha e exterioriza sua subjetividade na matéria. As produções e as significações das gerações anteriores darão elementos para a construção de sua consciência individual.

A educação, então, seria o processo pelo qual o homem se humaniza tendo como base o patrimônio cultural de gerações passadas e o construído pela sociedade ao qual está inserido. A atividade deveria desenvolver, concomitantemente, o potencial do professor e do aluno; para tanto, o motivo da atividade de ensino deve coincidir com a ação do professor e requer que o aluno perceba a necessidade desta aprendizagem. Para Leontiev (1978, p.130), a “consciência individual só pode existir nas condições de uma consciência social; é apropriando-se da realidade que o homem a reflete como através do prisma das significações elaboradas socialmente".

O desenvolvimento da produção metal gera certas necessidades que só podem existir na presença de um 'plano de consciência'. Finalmente, forma-se um tipo especial de necessidade-necessidades que são objetivo-funcionais, como necessidade de trabalho, de criação artística, etc. (LEONTIÉV, 1978, p.16)

E a atividade pedagógica? Neste contexto, é a atividade que proporciona a aprendizagem de conteúdos que devem ser transmitidos aos alunos para que apropriarem-se de saberes e produtos culturais a fim de "humanizarem-se". Esta perspectiva reitera o papel do professor, do conteúdo e importância da didática não para reinventar ou introduzir novos métodos de ensino, mas para efetivar a aprendizagem. Para tanto, a educação deve levar em consideração tanto o significado quanto o sentido pessoal da atividade.

Há de existir uma relação entre o significado social e o sentido pessoal, ou no caso contrário, percebe-se a questão da alienação tão contundente na sociedade contemporânea. Assim, ao analisarmos a atividade do sujeito, faz-se necessário descobrir qual é o motivo gerador do sentido pessoal" (DUARTE, 2013. p. 36).

Existe uma problemática no contexto escolar: excesso de conteúdos e pouca didática ou ênfase no método e pouco conteúdo. O ensino deve ser valorizado, mas, sobretudo, a aprendizagem deste ensino, através de teorias que respondam como o aluno aprende realmente e o que deve aprender para que haja uma transformação em nível pessoal e 
coletivo. A atividade pedagógica precisa incorporar-se de teorias que expliquem o processo de aprendizagem e que sejam passíveis de serem aplicadas no cotidiano escolar.

\section{CONCLUSÕES}

Ao relacionarmos Teoria Psicológica da Atividade de Leontiev com Pedagogia Histórico-crítica, podemos verificar o quanto a dimensão didática da educação precisa considerar elementos intrapsíquicos e sociais para promover a aprendizagem. Os conteúdos, o motivo, o contexto, o aluno e o professor são percebidos como agentes ativos na construção de saberes. A Pedagogia Histórico-crítica e a Psicologia Histórico-cultural, ao valorarem a escola, os saberes historicamente construídos e a prática social, divergem de tendências pedagógicas que visam o individualismo e o esvaziamento do papel dos docentes, das instituições e da comunidade escolar na eleição de suas prioridades educativas, o que corrobora para a adaptação e aceitação de valores sociais vigentes.

Percebemos uma inter-relação entre aprendizagem e desenvolvimento social assim como entre a formação dos processos mentais e os processos do conhecimento. Assim, lemas tão comuns no contexto escolar como "ninguém educa ninguém" ou "todos se educam juntos" são vistos de forma negativa. Aprender, neste contexto, é aprender a pensar e atuar com conceitos, com conteúdos e a partir da realidade, fato que exige uma intervenção intencional dos professores para assegurar mudanças nos processos mentais dos alunos através de uma mediação didática que objetive atitudes reflexivas e que promova suas capacidades através dos conteúdos. Assim, ao invés de memorização, a aquisição do conhecimento ocorre através de um processo gradual.

Diferentemente dos modelos construtivistas, o centro do conhecimento são os conteúdos, uma vez que estes são oriundos de pesquisas, de práticas e de resultados obtidos pelos homens ao longo do tempo e, portanto, devem ser transmitidos pela educação, cabendo ao professor estabelecer uma relação entre aluno e esta matéria a ser ensinada e aprendida. $\mathrm{O}$ compromisso da escola é promover uma educação integral, capaz de ensinar a pensar, refletir, criar e não executar somente. Em oposição às tendências pedagógicas que esvaziam a escola tanto de conteúdos quanto de inquietações, busca contrapor o conformismo, a padronização e a falta de conteúdos, base para a concretização da aprendizagem.

Deve-se ter em conta que a teoria da atividade não é uma pedagogia. Entre ela e a prática educativa existe uma teoria pedagógica e, no caso, a mais compatível com seus pressupostos é a Pedagogia Histórico-crítica. Busca a socialização do conhecimento artístico, 
filosófico e científico e percebe que a aprendizagem se relaciona com questões psíquicas e sociais, desenvolvendo estudos que abordam as contradições existentes no próprio processo de ensino e aprendizagem. É na atividade que o homem se desenvolve, portanto, é a partir dela, refletindo e repensando-a que podemos potencializar as capacidades deste "homem humano" em constante formação e transformação.

\section{REFERÊNCIAS BIBLIOGRÁFICAS}

ALMEIDA, Guido de. O professor que não ensina. São Paulo: Summus, 1986.

CHARLOT, Bernard. Relação com o saber, formação dos professores e globalização: questões para educação hoje. Porto Alegre: Artmed, 2005.

DUARTE, Newton. A individualidade para si: contribuição a uma teoria histórico-social da formação do indivíduo. Campinas: Autores Associados, 2013.

. As pedagogias do aprender a aprender e algumas ilusões da assim chamada sociedade do conhecimento. XXIV Reunião Anual da ANPEd, Caxambu, 2001. Disponível em: 〈http://www.scielo.br/pdf/rbedu/n18/n18a04> . Acesso em 06 jun 2016.

FRIGOTTO, G. A produtividade da escola improdutiva: Um (re) exame das relações entre educação e estrutura econômico-social capitalista. São Paulo: Cortez, 2010.

. Os delírios da razão: crise do capital e a metamoose conceitual no campo

educacional. In: GENTILI, P. Pedagogia da exclusão, crítica neoliberalismo em educação. 15 edições, Petrópolis: Vozes, 2008.

LEONTIEV, A. N. Actividad, conciencia y personalidad. Buenos Aires: Ed. Ciências del Hombre, 1978.

Ícone/Edusp, 2014.

Linguagem, desenvolvimento e aprendizagem. $13^{\mathrm{a}}$ ed. São Paulo:

O desenvolvimento do psiquismo. Lisboa: Livros Horizonte, 1978.

LOMBARDI, José Claudinei \& SAVIANI, Demerval (orgs). Marxismo e educação: debates contemporâneos. Campinas: Autores Associados: HISTEDBR, 2005.

LONGAREZI, Andréa Maturano; PUENTES, Roberto Valdés (org). Ensino Desenvolvimental: vida, pensamento e obra dos principais representantes russos. Uberlândia: EDUFU, 2015.

RIOS, Terezinha Azeredo. A dimensão ética da aula ou o que nós fazemos com eles. In: VEIGA, Ilma P. A. (org.) Aula: gênese, dimensões, princípios e práticas. Campinas: Papirus, 2008 . 
SAVIANI, Demerval. Escola e Democracia. Campinas: Autores Associados, 2009.

Pedagogia histórico-crítica: primeiras aproximações. Campinas:

Autores Associados, 2012.

SEVERINO, Antônio Joaquim. A busca do sentido da formação humana: tarefa da

Filosofia da Educação. Educação e Pesquisa, São Paulo, v. 32, n3, set/dez, 2006. Disponível em: <http://www.scielo.br/scielo.php?script=sci_arttext\&pid=S1517-97022006000300013>. Acesso em: 11 de novembro de 2016.

TRIVINOS, Augusto Silva. A dialética materialista e a prática social. Movimento, Porto Alegre, v.12, n. 02, p. 121-142, maio/agosto de 2006.

VYGOTSKI, L. S. A formação social da mente. 7 a . Ed. São Paulo: Martins Fontes, 2007. Historia del desarrollo de las funciones psíquicas superiores. Madrid:

Visor, 1995. Obras escogidas. Madrid: Editora Visor, 1991. 